\title{
Morbidity and mortality amongst infants of diabetic mothers admitted into a special care baby unit in Port Harcourt, Nigeria
}

Peace I Opara ${ }^{*}$, Tamunopriye Jaja ${ }^{\dagger}$, Uche C Onubogu ${ }^{\dagger}$

\begin{abstract}
Background: Infants born to diabetic women have certain distinctive characteristics, including large size and high morbidity risks. The neonatal mortality rate is over five times that of infants of non diabetic mothers and is higher at all gestational ages and birth weight for gestational age (GA) categories.

The study aimed to determine morbidity and mortality pattern amongst infants of diabetic mothers (IDMS) admitted into the Special Care Baby Unit of University of Port Harcourt Teaching Hospital.

Methods: This was a study of prevalence of morbidity and mortality among IDMs carried out prospectively over a two year period. All IDMs (pregestational and gestational) admitted into the Unit within the period were recruited into the study.

Data on delivery mode, GA, birth weight, other associated morbidities, investigation results, treatment, duration of hospital stay and outcome were collated and compared with those of infants of non diabetic mothers matched for GA and birth weight admitted within the same period. Maternal data were reviewed retrospectively. Data were analyzed using SPSS 16.0 .

Results: Sixty percent of the IDMs were born to mothers with gestational diabetes, while $40 \%$ were born to mothers with pregestational DM. 38 (74.3\%) were born by Caesarian section (CS), of which 20 (52.6\%) were by emergency CS. There was no significant difference in emergency CS rates, when compared with controls, but nonIDMs were more likely to be delivered vaginally. The mean GA of IDMs was 37.84 weeks $\pm 1.88 .29(61.7 \%)$ of them were macrosomic. The commonest morbidities were Hypoglycemia (significantly higher in IDMs than non-IDMs) and hyperbilirubinaemia in 30 (63.8\%) and 26 (57.4\%) respectively.

There was no difference in morbidity pattern between infants of pre- gestational and gestational diabetic mothers. Mortality rate was not significantly higher in IDMs

Conclusions: The incidence of macrosomia in IDMs was high but high rates of emergency CS was not peculiar to them. Hypoglycaemia and hyperbilirubinaemia were the commonest morbidities in IDMs.

Referring women with unstable metabolic control to specialized centers improves pre- and post- natal outcomes. Maternal-Infant centers for management of diabetes in pregnancy are advocated on a national scale to reduce associated morbidity and mortality
\end{abstract}

\section{Background}

Diabetes has long been associated with maternal and perinatal morbidity and mortality [1]. Diabetes in Pregnant women could be either pregestational or gestational. Gestational diabetes accounts for about $80 \%$ of

\footnotetext{
* Correspondence: peaceibo@yahoo.com.au

† Contributed equally

Department of Paediatrics, University of Port Harcourt Teaching Hospital, Port Harcourt, Nigeria
}

(c) 2010 Opara et al; licensee BioMed Central Ltd. This is an Open Access article distributed under the terms of the Creative Commons Attribution License (http://creativecommons.org/licenses/by/2.0), which permits unrestricted use, distribution, and reproduction in any medium, provided the original work is properly cited. cases and could represent a predisposition to type 2 diachanges during pregnancy [2].

The incidence of impaired glucose tolerance in pregnancy is between $3-10 \%$ and varies according to the incidence of diabetes in the general population [3]. In a study in Nigeria; an incidence of $1.7 \%$ was recorded with pregestational diabetes accounting for $39 \%$ and gestational diabetes for $61 \%$ [4]. 
In an American maternal and infant survey in 1988, $4 \%$ of live births were associated with diabetes mellitus, $88 \%$ of these were cases of gestational diabetes, $8 \%$ were non insulin dependent (type $2 \mathrm{DM}$ ) and $4 \%$ were insulin dependent (type $1 \mathrm{DM}$ ) [5].

Perinatal mortality amongst offspring of diabetic mothers has remained high and was previously an indication for termination of pregnancy. The cause of increased perinatal morbidity and mortality is not known but has been attributed to increased insulin levels leading to hyper anabolism. Studies have shown higher mortality amongst infants of diabetic mothers compared to controls $[1,4,6]$. In the study in Nigeria, the perinatal mortality was found to be $12.5 \%$ compared to $3.5 \%$ in controls [4]. Perinatal outcome associated with poor glycaemic control in mothers is associated with as high as $49.2 \%$ mortality [4].

The major morbidities associated with infants of diabetic mothers include respiratory distress, growth restrictions, polycythaemia, hypoglycaemia, congenital malformations, hypocalcaemia, hypomagnesaemia. However associated macrosomia and increased prevalence of caesarean sections contribute to higher mortality [6,7].

In view of the high morbidity and mortality associated with this condition babies born to diabetic mothers delivered in the University of Port Harcourt Teaching Hospital were studied, to determine common morbidities and need for closer monitoring of these babies.

\section{Methods}

This was a study of prevalence of morbidity and mortality among IDMs, carried out prospectively in the Special Care Baby Unit (SCBU) of the University of Port Harcourt Teaching Hospital between January 2008 and December 2009. Port Harcourt is a cosmopolitan city situated in Rivers State in the southern part of Nigeria. It has a land area of 170 square kilometer with a population of approximately three million, seven hundred and sixty one thousand, six hundred and Forty five. The Hospital is the largest tertiary hospital in the state and serves as a tertiary as well as a general hospital for South- South Nigeria. The SCBU caters for sick newborn infants in the University of Port Harcourt Teaching Hospital and serves as a referral centre for neonates in Port Harcourt and its environs.

All infants of diabetic mothers admitted into the Unit within the period, were consecutively recruited into the study. Informed consent was obtained from the mothers/caregivers and they all gave consent for infant participation in the study. Babies of mothers with pregestational diabetes mellitus (Type 1 and Type 2) and gestational diabetes (GDM) were included. Maternal data were reviewed retrospectively. Information obtained included: a) characteristics of the mothers; age, parity, type and duration of diabetes, treatment received, presence or absence of other illnesses, pregnancy complications, mode of delivery, maternal outcome and b) characteristics of the babies; gestational age, birth weight, diagnosis, results of investigations, treatment received, duration of hospital stay and outcome. For each IDM, an infant of a non diabetic mother admitted into the unit within the same period, matched for gestational age, and birth weight was recruited as control. Sometimes, one infant was used as control for more than one IDM.

Patients were classified into large for gestational age (LGA), appropriate for gestational age (AGA), and small for gestational age (SGA), according to the relationship between intrauterine growth and gestational age $[8,9]$. Infants whose birth weights were at least $4000 \mathrm{~g}$ regardless of gestational age were defined as macrosomic, while those who weighed less than $2500 \mathrm{~g}$ were defined as low birth weight.

Investigations done included; random blood glucose, chest radiographs, serum electrolytes, serum bilirubin, complete blood counts and blood cultures. Some of these were done only where applicable. Hypoglycaemia was defined as blood glucose concentrations $<2.6 \mathrm{mmol} /$ 1, Polycythaemia was defined as a peripheral venous hematocrit greater than 0.65 , and hyperbilirubinaemia was defined as serum levels of indirect bilirubin greater than $204 \mu \mathrm{mol} / \mathrm{L}(12 \mathrm{mg} / \mathrm{dl})$ and/or any hyperbilirubinaemia requiring treatment (phototherapy and/or exchange blood transfusion). Hypocalcaemia was defined by total serum calcium values lower than $1.50 \mathrm{mmol} / \mathrm{L}$ (6 mg/dL). Routine echocardiography could not be done for the babies due to cost and unavailability of the facilities for paediatric echocardiography in the hospital at the time of the study. All babies who were asphyxiated, had significant respiratory distress, or whose mothers were too ill to breastfeed were placed on dextrose infusions until they or their mothers were fit to feed and breast feeding had been well established. All the babies were fed exclusively on breast milk in line with the Hospital's breast feeding policy.

Hypoglycaemia was corrected with $10 \%$ dextrose water while hypocalcaemia was corrected with $10 \%$ calcium gluconate. All babies with suspected sepsis were placed on broad spectrum antibiotics till blood culture results were reviewed. Data were entered into a Microsoft excel spreadsheet and analysed using SPSS version 16.0. Statistical level of significance was set at $\mathrm{p}$ value of 0.05 or less.

\section{Results}

The age range of the mothers of IDMs was $26-45$ years with a mean of $33.15 \pm 4.17$ years. All the mothers received antenatal care in the University of Port 
Harcourt Teaching Hospital either primarily or had been referred from other peripheral hospitals because of a bad obstetric history or because they were diabetics. $31.9 \%$ of the mothers of IDMs were primiparous. Eighteen $(38.3 \%)$ had pregestational DM, while 29 (61.7\%) had gestational DM. 31 (66\%) had received insulin during pregnancy. Mean blood glucose levels of the mothers as at their last antenatal visit was $11.65 \pm 5.19$ with a range of $5.0-22.0 \mathrm{mmol} / \mathrm{l}$. Glycosylated haemoglobin $\left(\mathrm{HbA} 1_{\mathrm{C}}\right)$ levels were not routinely measured. Thirty eight mothers $(80.8 \%)$ delivered via Caesarean section either as emergency (42.5\%) or elective (38.3\%) while $28(59.6 \%)$ had had previous foetal or neonatal deaths. There was no maternal death. Table 1 shows the characteristics of the mothers.

Of the IDMs, 31 were males and 16 were females with a M: F ratio of 1.9:1. Gestational ages ranged from 31 41 weeks with a mean of $37.84 \pm 1.88$ weeks. The mean birth weight was $4.14 \mathrm{~kg} \pm 0.838(2.0-6.0 \mathrm{~kg}) .29$ (61.7\%) were macrosomic. Mean Apgar scores at 1 minute was $6.96 \pm 1.62$; and at 5 minutes, $8.45 \pm 1.16$. $91.5 \%$ of the babies were admitted into the ward within the first hour of birth. Duration of admission was 1-21 days with a mean of $6.97 \pm 2.63$ days.

Table 2 shows the general characteristics of the IDMs and duration of admission.

Table 1 characteristics of mothers of infants who were recruited into the study

\begin{tabular}{lcc}
\hline Characteristic & Number & Percent (\%) \\
\hline Parity & 15 & 31.9 \\
1 & 13 & 27.7 \\
2 & 6 & 12.8 \\
3 & 5 & 10.6 \\
4 & 8 & 17.0 \\
$\geq 4$ & 47 & 100 \\
Total & & \\
Type of diabetes & 29 & 61.7 \\
GDM & 10 & 21.3 \\
Type 1 & 8 & 17.0 \\
Type 2 & $\mathbf{4 7}$ & 100 \\
Total & & \\
Previous foetal/neonatal deaths & 20 & 42.5 \\
Foetal & 8 & 17.1 \\
Neonatal & 19 & 40.4 \\
None & $\mathbf{4 7}$ & $\mathbf{1 0 0}$ \\
Total & & \\
Mode of delivery & 18 & 38.3 \\
Elective CS & 20 & 42.5 \\
Emergency CS & 7 & 14.9 \\
Spontaneous vaginal & 2 & 4.3 \\
Assisted vaginal (vacuum) & $\mathbf{4 7}$ & $\mathbf{1 0 0}$ \\
Total & &
\end{tabular}

Table 2 Characteristics of infants of diabetic mothers

\begin{tabular}{lcc}
\hline Characteristics & Number & Percent (\%) \\
\hline Gestational age (weeks) & 7 & 14.9 \\
$<37$ & 37 & 78.7 \\
$37-41$ & 3 & 6.4 \\
$\geq 41$ & 47 & 100 \\
Total & & \\
Birth weight (kg) & 4 & 8.5 \\
$<2.5$ & 14 & 29.8 \\
$2.5-3.99$ & 29 & 61.7 \\
$\geq 4$ & 47 & 100 \\
Total & & \\
Feeding commenced (hours) & 14 & 29.8 \\
$<24$ & 19 & 40.4 \\
$24-72$ & 14 & 29.8 \\
$>72$ & 47 & 100 \\
Total & & \\
Duration of admission (days) & 11 & 23.4 \\
$\leq 3$ & 22 & 46.8 \\
$4-7$ & 14 & 29.8 \\
$\geq 7$ & 47 & 100 \\
Total & & \\
\hline
\end{tabular}

The commonest morbidities were hypoglycaemia 30 (63.8\%), neonatal jaundice 27 (57.4\%), and respiratory disorders 16 (34.0\%). Mean blood glucose levels of all IDMs within the first hour was $2.93 \pm 1.51 \mathrm{mmol} / \mathrm{l}$. Thirty (63.8\%) developed hypoglycaemia within the first 24 hours.

Of all the IDMs with neonatal jaundice, 14 were macrosomic and $4(14.8 \%)$ required exchange blood transfusion. There was no statistically significant difference in the occurrence of jaundice between macrosomic and non macrosomic babies $(\mathrm{p}=0.49)$. Respiratory distress was noted in $16(34.0 \%)$. There was radiological evidence of transient tachypnoea of the new born in 10 (62.5\%), congenital pneumonia in $5(31.3 \%)$ and respiratory distress syndrome in 1 (6.3\%).

Fifteen babies $(31.9 \%)$ had features suggestive of sepsis but only $3(0.2 \%)$ had culture proven sepsis. Mean PCV levels were $54.5 \% \pm 7.311$ (43-69\%). 5 (10.6\%) had polycythaemia, of which one had a partial exchange blood transfusion. Hypocalcaemia occurred in 11 (23.4\%) babies. Table 3 shows the morbidities and treatment received.

Mortality was recorded in 2 (4.3\%) of the babies. The babies who died were macrosomic and severely asphyxiated, and were delivered via emergency caesarean section following prolonged obstructed labour and late presentation to hospital.

There was no significant difference in the morbidity pattern between infants of pregestational and gestational diabetic mothers. Table 4 shows the clinical and 
Table 3 Morbidities and treatment received

\begin{tabular}{lcc}
\hline Diagnoses & Number & Percent (\%) \\
\hline Hypoglycaemia & 30 & 63.8 \\
Neonatal jaundice & 27 & 57.4 \\
Respiratory distress & 16 & 34.0 \\
Neonatal sepsis & 15 & 31.9 \\
Birth asphyxia & 7 & 14.9 \\
Polycythaemia & 5 & 10.6 \\
Birth injuries & 2 & 4.3 \\
Seizures & 1 & 2.1 \\
Hypocalcaemia & 11 & 23.4 \\
Hypomagnesemia & 5 & 10.6 \\
Hypophosphatemia & 4 & 8.5 \\
Others & 2 & 4.3 \\
Treatment & & \\
Phototherapy & 30 & 63.8 \\
Dextrose infusions & 47 & 100 \\
Antibiotics & 35 & 68.1 \\
Oxygen therapy & 7 & 14.9 \\
Calcium supplements & 11 & 23.4 \\
Exchange blood transfusion & 5 & 10.6 \\
\hline
\end{tabular}

biochemical characteristics of gestational and pregestational diabetic mothers/infants.

There were 22 controls with gestational ages ranging from $32-41$ weeks $(38.8 \pm 1.424)$ and a M:F ratio of $1: 1.5$. Their mean birth weight was $4.37 \pm 0.772$, (2.3 $-6.0 \mathrm{~kg})$, mean apgar scores at one minute were $5.95 \pm 2.12$ and at 5 minutes, $7.80 \pm 2.093$. Thirteen were macrosomic.

Table 5 shows a comparison of some parameters between IDMs and non- IDMs. Emergency caesarian section rates were also high in the non-IDMs, but they were more likely to be delivered vaginally. The commonest morbidities among the controls were birth asphyxia, neonatal Sepsis/infections and respiratory

Table 4 Clinical and biochemical characteristics of pregestational and gestational diabetic mothers/infants

\begin{tabular}{lccc}
\hline & $\begin{array}{c}\text { Pregestaional DM } \\
\mathbf{N}=\mathbf{1 8}\end{array}$ & $\begin{array}{c}\text { Gestational DM } \\
\mathbf{N}=\mathbf{2 9}\end{array}$ & p value \\
\hline Mode of delivery & & & \\
EMCS & 8 & 12 & 0.895 \\
ELCS & 6 & 12 & 0.71 \\
SVD & 4 & 4 & 0.53 \\
Birth weight $(\mathbf{k g})$ & & & \\
$<2.5$ & 2 & 2 & 0.64 \\
$2.5-3.99$ & 7 & 9 & 0.70 \\
$\geq 4.0$ & 9 & 18 & 0.67 \\
Hypoglycaemia & 8 & 18 & 0.52 \\
Normoglycaemia & 10 & 11 & 0.47 \\
Jaundice & 11 & 14 & 0.63 \\
\hline
\end{tabular}

Table 5 Comparison of delivery mode and common morbidities between IDMs and non-IDMs

\begin{tabular}{lccc}
\hline & $\begin{array}{c}\text { IDMS } \\
\mathbf{N}=\mathbf{4 7}\end{array}$ & $\begin{array}{c}\text { Non-IDMs } \\
\mathbf{N}=\mathbf{2 2}\end{array}$ & P value \\
\hline Delivery mode & 20 & 10 & 0.926 \\
EMCS & 18 & 2 & 0.098 \\
ELCS & 4 & 10 & 0.013 \\
SVD & & & \\
Common Morbidities & 26 & 3 & 0.048 \\
Hypoglycemia & 25 & 4 & 0.109 \\
Neonatal jaundice & 16 & 8 & 0.902 \\
Neonatal sepsis/infections & 16 & 8 & 0.902 \\
Respiratory distress & 7 & 8 & 0.202 \\
Birth asphyxia & 2 & 3 & 0.328 \\
Birth injuries & 2 & 0 & 1.000 \\
Mortality & & & \\
\hline
\end{tabular}

distress. Transient tachypnoea of the newborn and pneumonia accounted for all the cases of respiratory distress. There was no case of respiratory distress syndrome or polycythaemia. There was no mortality recorded in the control group.

\section{Discussion}

This study shows that 28 (59.6\%) of the diabetic mothers had had previous foetal or early neonatal deaths, this being one of the reasons (as documented in their case notes) for referral of some of them to our centre. This shows that diabetes still contributes significantly to perinatal and neonatal mortality in our environment. The study also showed a low mortality rate among IDMs, although still higher than in the nonIDMs. Although perinatal mortality among this group has declined $[10,11]$, neonatal morbidity remains a significant challenge [12-14].

There was a high incidence of macrosomia among IDMs in this study. This finding is similar to that in another Nigerian study [5]. Macrosomia remains an important morbidity because it is associated with increased risk for traumatic birth injury, obesity, and diabetes in later life [12]. Although some of the variation in incidence may be related to definition, most authors agree that macrosomia is in part related to maternal glucose control $[15,16]$.

Glycaemic control in our mothers was difficult to ascertain since only blood glucose levels done during antenatal visits were documented and glycosylated haemoglobin $\left(\mathrm{HbA} 1_{\mathrm{C}}\right)$ levels were not routinely measured. In centers that have coordinated diabetes-in-pregnancy programmes which stress good maternal glycaemic control, the incidence of macrosomia is reduced [17]. The high rates of macrosomia in this study may therefore reflect poor glycaemic control in the mothers. 
The caesarian section (CS) rate in this study was very high with emergency CS rates being higher than elective CS rates even amongst the controls. The high rate of operative deliveries, similar to the other Nigerian study [5] is related to the high incidence of macrosomia in the IDMs and their matched controls. Our findings were however in contrast to the findings in a Sri-Lankan study [18] where elective CS rates were much higher than emergencies. Sri Lanka holds a unique place in South Asia as one of the first of the less developed nations to provide universal health [19]. In our environment women usually register late for ANC and the acceptability of operative deliveries is very low [5,20-22].

Thus, a woman booked for an elective CS will often show up when an emergency CS is inevitable.

Hypoglycaemia was the commonest neonatal problem recorded in the IDMs, occurring in significantly higher proportions than in the non-IDMs. The high rate of hypoglycaemia in our IDMs is similar to findings by other authors $[13,14,18]$ and has been identified as a marker of poor glycaemic control in the mother. A rapid decline in plasma glucose concentration is characteristic of the IDM, especially one whose mother's diabetes is poorly controlled $[10,13]$. Maternal hyperglycemia leads to foetal hyperglycaemia, stimulating the foetal pancreas to synthesize excessive insulin. With separation of the placenta at birth, there is a sudden interruption of glucose infusion to the neonate without a proportional effect on hyperinsulinemia $[10,13]$. Thus hypoglycaemia develops within the first hours of birth. Although there were no proper records of peripartum glucose levels in our mothers, mean blood glucose levels were high and the high rates of neonatal hypoglycaemia may also be a reflection of poor maternal glycaemic control.

Hypocalcemia was the other common metabolic problem in this study. It has also been documented as a problem of IDMs by other authours [13,14,23,24]. Tsang et al [25] advanced the hypothesis that hyperparathyroidism of diabetic mothers might suppress the foetal parathyroid function and lead to hypocalcaemia of the newborn.

Neonatal jaundice was noted very frequently in our IDMs, irrespective of the type of maternal diabetes. Its incidence was however not significantly higher than in the control group, probably because these were matched controls who had been admitted for other illnesses, like jaundice from blood group incompartibilities and also probably because of our small sample size. The high rates of jaundice in our IDMs was in contrast with another African study where it occurred in only $29 \%$ of cases. The reason for this contrast is not clear. Hyperbilirubinaemia is a recognised problem of infants of diabetic mothers, and has been shown to occur with increased frequency in macrosomic infants of diabetic mothers [26,27]. Hyperbilirubinemia occurred in about half of our macrosomic IDMs although this association was not statistically significant.

Congenital pneumonia and transient tachypnoea of the newborn (TTN) were common causes of respiratory distress in all the babies this study. This is not surprising as infections, to which IDMs are also at increased risk play a major role in neonatal morbidity and mortality in our environment [28]. TTN is a known complication of IDMs especially following caesarean section deliveries [23]. There was also a high rate of TTN among the controls, which was expected because most of them were also macrosomic and delivered by caesarian section, which on its own is a known risk factor.

TTN was also common in a similar study done in Harare [24]. However studies done outside Africa $[13,18]$ recorded respiratory distress syndrome as the commonest cause of respiratory distress amongst IDMs. The Harare study [24] did not record any case of respiratory distress syndrome while we recorded only one case and none among the non-IDMs. This may buttress the fact that although RDS is one of the commonest causes of respiratory distress in other races, it is uncommon in Africa [29].

There were no obvious congenital malformations in our study. The incidence of major congenital malformations has been reported to be 2-5 times greater in IDMs than in other infants with cardiac malformations recorded as the most common [30,31]. The unavailability of routine echocardiography in this study may have missed out cases of asymptomatic congenital cardiac malformations. The incidence was also high in the other Nigerian study [5]. This may also be because they studied outcome in pregnant women whilst we studied only babies admitted into our unit, thereby also possibly excluding malformations which were not compatible with life. The Harare study [24] however also recorded a low incidence of life threatening congenital malformations.

The study did not show any significant difference in morbidity pattern between infants of mothers with pregestational diabetes and those with gestational diabetes. This is a pointer to the need for screening of all pregnant women for diabetes and also anticipatory and active management of infants of diabetic mothers irrespective of type of maternal diabetes. The mortality rate was lower among the non IDMs but the difference was not statistically significant. This shows that with proper care, live born IDMs without major congenital malformations have a good chance of survival. 


\section{Conclusions}

The study shows a high incidence of macrosomia, hypoglycaemia and hyperbilirubinaemia but absence of obvious congenital abnormalities in IDMs. They were more likely to be delivered by Caesarian sections than non- IDMs but rates of emergency CS among the two groups were similar. Morbidity pattern was identical in both infants of pregestational and gestational diabetes mellitus.

Screening of all pregnant women for diabetes, good glycaemic control and active management of their infants will reduce perinatal morbidity and mortality. Opening of maternal-infant centres with standard protocols for prevention and treatment of diabetes in pregnancy on a national scale will go a long way in reducing the scourge of this condition.

\section{Acknowledgements}

The authors acknowledge the staff of the Special Care Baby Unit, University of Port Harcourt Teaching Hospital for co-operation received in the course of the study.

\section{Authors' contributions}

$\mathrm{PIO}$, UCO contributed to conception, design and acquisition of data. $\mathrm{PIO}, \mathrm{TJ}$ did the analysis and interpretation of data and were involved in drafting the manuscript.

All authors participated in reading and revising the manuscript and gave final approval of the version to be submitted.

\section{Competing interests}

The authors declare that they have no competing interests.

Received: 7 June 2010 Accepted: 7 December 2010

Published: 7 December 2010

\section{References}

1. Butle NF: Carbohydrate and lipid metabolism in pregnancy: normal compared with gestational diabetes mellitus. Am J Clin Nutr 2000, 71(5):12565-12615

2. Catalano PM, Tyzbor EP, Wolf RR, Roman NM, Amini SB, Sims EAH: Longitudinal changes in basal hepatic glucose production and suppression during insulin infusion in normal pregnant women. Am J Obstet Gynecol 1992, 167:913-3.

3. Thorpe LE, Berger D, Ellis SA, Bethegowda VR, Brown G, Matte T, Basset M, Frieden TR: Trends and racial/ethnic disparities in gestational diabetes among pregnant women in New York City, 1990-2001. Am J Pub Hith 2005, 95(5):1536-1539.

4. Ferrara A, Hedderson MM, Selby JV: Prevalence of gestational diabetes mellitus detected by National Diabetes Data group or the carfactor and couston plasma glucose threshold. Diabetes Care 2002, 25(9):1625-1630.

5. Ozumba BC, Obi SN, Olu JM: Diabetes mellitus in pregnancy in an African population. Int S Gynaecol Obstet 2004, 84(2):114-119.

6. Otolorun EO, Famuyiwa OO, Bello AF, Da-Wodu AH, Adelusi B: Reproductive performance following active management of diabetic pregnancies at UCH, Ibadan, Nigeria. Afr J Med Sci 1985, 14(3-4):155-60.

7. Engelgau MM, Herman NH, Smith PJ, German RR, Aubert RE: The epidemiology of diabetes and pregnancy in US. 1988. Diabetes Care 1995, 18(7):1029-1033.

8. Battaglia FC, Lubchenco LO: A practical classification of newborn infants by weight and gestational age. J Pediatr 1967, 71:159-163.

9. Ballard JL, Khoury JC, Wedig K, et al: New Ballard Score, expanded to include extremely premature infants. J Pediatr 1991, 119:417-423.
10. Landon MB, Gabbe SG, Piana R, Mennuti MT, Main EK: Neonatal morbidity in pregnancy complicated by diabetes mellitus: predictive value of maternal glycemic profiles. Am J Obstet Gynecol 1987, 156:1089-1095.

11. Gregory R, Scott AR, Mohajer M, Tattersall RB: Diabetic pregnancy 19771990: have we reached a plateau? J R Coll Physicians Lond 1992, 26:162-166.

12. Hod M, Merlob P, Friedman S, Schonfeld A, Ovadia J: Gestational diabetes mellitus: a survey of perinatal complications in the 1980s. Diabetes 1991, 40:74-78.

13. Cordero L, Landon MB: Infant of diabetic mother. Clin Perinato/ 1993, 20:635-648.

14. Nasrat HA, Salleh M, Ardawi M, Ghafouri H: Outcome of pregnancy in diabetic mothers. Int J Gynaecol Obstet 1993, 43:29-34.

15. 12 Neiger R: Fetal macrosomia in the diabetic patient. Clin Obstet Gynecol 1992, 35:138-150.

16. Gyves MT, Rodman HM, Little AB, Fanaroff AA, Merkatz IR: A modern approach to management of pregnant diabetics: a two-year analysis of perinatal outcomes. Am J Obstet Gynecol 1977, 128:606-616.

17. Cordero L, Treuer SH, Landon B, Gabbe S: Management of infants of diabetic mothers. Arch Pediatr Adolesc Med 1998, 152:259-254.

18. Senanayake MP, Gunawardene MKS: Neonatal morbidity following control of maternal diabetes mellitus with human insulin. Sri Lanka Journal of Child Health 2000, 29:11-14

19. Samarage SM: Migration and human resources for health: From awareness to action. CCIG Geneva 2006.

20. Feresu SA, Gillespie BW, Sowers MF, Johnson TRB, Welch K, Harlow SD, Improving assessment of gestational age in a Zimbabwean population: Int $J$ Obstet Gynaecol 2002, 78:7-18.

21. Azikem M, Omo-aghoja L, Okonofua F: Perception and attitudes of pregnant women towards caesarian sections in urban Nigeria. Acto Obstetrica et Gynecologica Scandinavica 2007, 86:42-47.

22. Awoyinka BS, Ayinde OA, Omigbodun AO: Acceptability of Caesarian delivery to antenatal patients in a tertiary health facility in South-West Nigeria. J Obstet Gynaecol 2006, 26:208-210.

23. Stoll BJ, Kliegman RM: Infants of diabetic mothers. In Nelson Textbook of Paediatrics. 17 edition. Edited by: Behrman RE, Kliegman RM. Philadelphia Saunders; 2003:614-616.

24. Rutherford MA, Chawla V: Infants of diabetic mothers: a prospective study of neonatal complications in Harare, Zimbabwe. Ann Trop Pediatr 1989, 9(4):191-193.

25. Tsang RC, Kleinman LI, Sutherland JM, Light IJ: Hypocalcaemia in infants of diabetic mothers: studies in calcium, phosphorus and magnesium metabolism and parathormone reponsiveness. J Pediatr 1972, 80:384-395.

26. Soler NG, Soler SM, Malins JM: Neonatal morbidity in infants of diabetic mothers. Diabetes Care 1978, 1:340-350.

27. Peevy KJ, Landaw SA, Gross GJ: Hyperbilirubinaemia in infants of diabetic mothers. Pediatrics 1980, 66:417-419.

28. Lawn JE, Cousens S, Zupan J: 4 Million neonatal deaths: When? Where? Why? Lancet 2005, 365:891-900.

29. Dawodu AH, Ogunbiyi O: Respiratory distress in a special care baby unit in Nigeria. Ann Trop Pediatr 1984, 4(1):1-5

30. Cousins L: Biology and prevention of congenital anomalies among infants of overt diabetic women. Clin Obstet Gynecol 1991, 34:481-483.

31. Reece EA, Homko CJ: Infant of diabetic mother. Semin Perinatol 1994, 18:459-469.

doi:10.1186/1824-7288-36-77

Cite this article as: Opara et al:: Morbidity and mortality amongst infants of diabetic mothers admitted into a special care baby unit in Port Harcourt, Nigeria. Italian Journal of Pediatrics 2010 36:77. 